\title{
BONE GRAFT HARVESTING: A PERCUTANEOUS TECHNIQUE
}

\section{MICHAEL SALEH}

Bone graft donor sites are often a source of significant morbidity. The incidence of donor site complications in one series was $9.4 \%$ and included chronic wound pain and hypersensitivity, buttock anaesthesia, muscle herniation, meralgia paraesthetica (Weikel and Habal 1977) and even subluxation of the hip (Cockin 1971). In another series, chronic donor site pain was reported in $25 \%$ of patients and was associated particularly with tricortical grafts (Summers and Eisenstein 1989).

In Sheffield over the past three years we have used a limited percutaneous approach to harvest cancellous bone. The technique relies on the use of the Meunier trephine first described for taking bicortical iliac bone biopsies (Jowsey 1977). The needle has four parts (Fig. 1); a flanged trephine with an $8 \mathrm{~mm}$ internal diameter, a blunt trocar (above), and an outer sleeve with a sharp introducer (below). The flange on the trephine is used as a handle when cutting the graft and provides a stop to prevent penetration of the soft tissues within the pelvis.

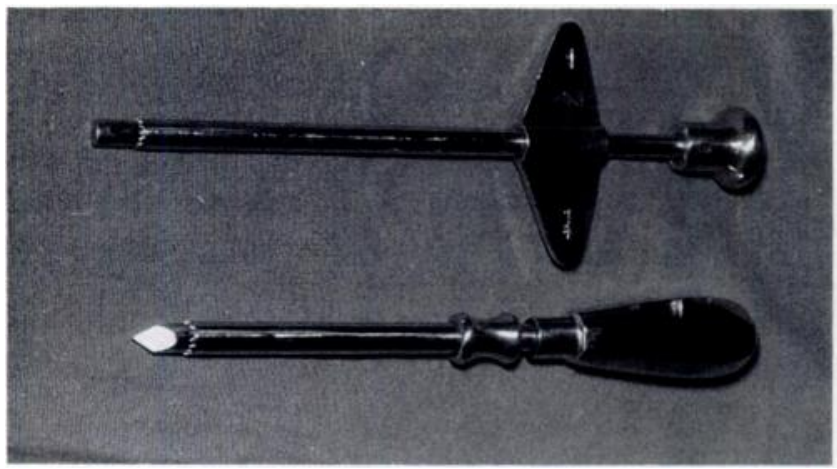

Fig. 1

The blunt trocar is used to deliver the graft. A single core will have a volume ranging from 0.6 to $1.2 \mathrm{ml}$ depending on the width of the bone (Fig. 2). As many as five cores may be taken if the incision is extended to $3 \mathrm{~cm}$.

Method. A $2 \mathrm{~cm}$ incision is made, $5 \mathrm{~cm}$ from the anterior superior iliac spine and $2 \mathrm{~cm}$ below the iliac crest. The deep fascia is incised and a pair of dissecting scissors is passed perpendicular to the wound and down to the bone.

M. Saleh, MSc, FRCS, FRCS Ed, Senior Orthopaedic Lecturer and Honorary Consultant

The Limb Reconstruction Service, University Department of Orthopaedics, Northern General Hospital, Herries Road, Sheffield S5 7AU, England.

(C) 1991 British Editorial Society of Bone and Joint Surgery $0301-620 X / 91 / 5 R 25 \$ 2.00$

J Bone Joint Surg [Br] 1991 ; 73-B : 867-8.
A passage is made in the soft tissues by opening the points of the scissors and stretching the soft tissues. The outer sleeve and pointed trocar are inserted down to the bone. The sleeve is held on the outer table, pointing slightly upwards because of the obliquity of the iliac wing. The pointed trocar is replaced by the trephine. The trephine is advanced by alternating rotary movements to core through the outer table and across the cancellous bone to the inner table (Fig. 3). The trephine is gently twisted and levered to separate the core. The core is extracted with the blunt trocar. The wound may be infiltrated with local anaesthesia and must be drained. If a $3 \mathrm{~cm}$ or larger incision is made, fascia as well as skin is closed.

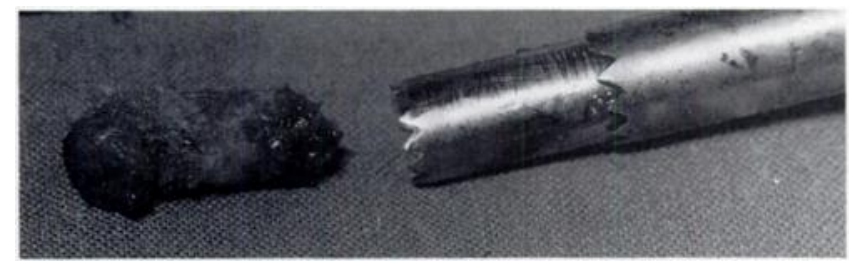

Fig. 2

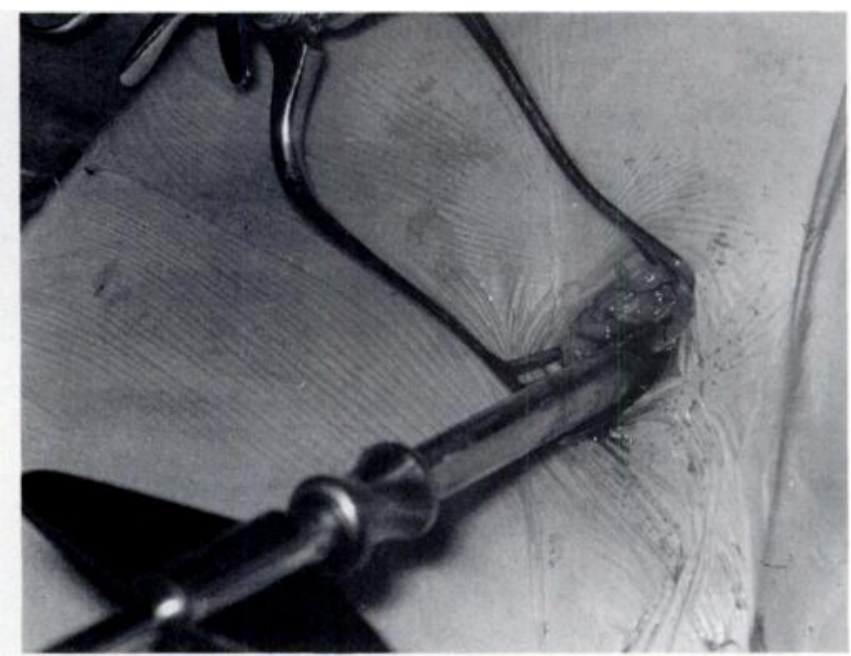

Fig. 3

Discussion. Percutaneous techniques of bone graft procurement have been reported in hand surgery; 2 to $3 \mathrm{~mm}$ grafts (Braun 1974) and $12 \mathrm{~mm}$ and $16 \mathrm{~mm}$ Cloward type dowels (Brody and Hentz 1990). This report describes the use of $8 \mathrm{~mm}$ grafts taken with a Meunier trephine. It has been used routinely for bone graft harvesting with the exception of those cases requiring more than $10 \mathrm{ml}$ of bone or those where structurally designed grafts are 
required. In the first 40 cases there have been no complications except that one wound which was not drained developed a painful haematoma which had resolved completely at the six-week review.

The technique enables adequate amounts of bone to be harvested more rapidly and with less surgical trauma and postoperative pain. It is recommended in limb surgery and its use may lower the surgeon's threshold for grafting acute fractures.

No benefits in any form have been received or will be received from a commercial party related directly or indirectly to the subject of this article.

\section{REFERENCES}

Braun RM. Trephine techniques for small bone grafts. The Hand 1974; 6:103-5.

Brody GA, Hentz VR. Cloward technique for obtaining iliac crest bone graft in hand surgery. J Hand Surg [ Am] 1990; 14-A:181-3.

Cockin J. Autologous bone grafting: complications at the donor site. $J$ Bone Joint Surg [Br] 1971; 53-B:153.

Jowsey J, ed. The bone biopsy. New York, etc: Plenum, 1977.

Summers BN, Eisenstein SM. Donor site pain from the ilium: a complication of lumbar spinal fusion. J Bone Joint Surg [Br] 1989; 71-B:677-80

Weikel AM, Habal MB. Meralgia paresthetica: a complication of iliac bone procurement. Plast Reconstr Surg 1977; 60-572-4. 